\title{
Applying The Technology Acceptance And Service Quality Models To Live Customer Support Chat For E-Commerce Websites
}

Ahmed Elmorshidy, Ph.D., Claremont Graduate University, USA \& Gulf University for Science \& Technology, Kuwait

\begin{abstract}
This study investigates Live Customer Support Chat as a new type of customer service implemented for E-commerce websites. This study addresses an important research gap in regards to the effectiveness of new live customer support technology compared to the traditional non real-time support types such as online forms and e-mail. The study used two well-known theoretical frameworks (The Technology Acceptance Model and the Service Quality Model) and created a new dimension of E-Service quality that is based on system quality, system reliability, system availability, information quality, consistency of service quality, and online customer feedback to build a new theoretical framework for Live Customer Support Chat. The study further introduces the dimensions of e-service quality and incorporates them in this new framework.
\end{abstract}

Keywords: Live Customer Support Chat; Technology Acceptance Model; Service Quality Model

\section{INTRODUCTION}

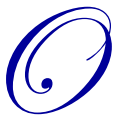

nline chat may refer to any kind of communication over the Internet which offers an instantaneous transmission of text-based messages from sender to receiver; hence the delay for visual access to the sent message shall not hamper the flow of communications in any of the directions. (Andrews 2010) Online chat may address as well point-to-point communications as well as multicast communications from one sender to many receivers. Interest in customer service chat for use on e-commerce websites has grown significantly in recent years. It is viewed as a cost-effective way to reduce purchasing risk through increasing social interaction, responsiveness to consumer questions, and personalization of the shopping experience. However, there is little evidence demonstrating that this customer service solution improves the online shopping experience, reduces perceived purchase risk or that it reduces purchase abandonment rates. (Andrews 2010) This study is among the first to fill this research gap by examining the benefits and barriers of live customer support chat. It also validates this new type of customer service through the well-established service quality model.

According to CRM.com, in customer relationship management (CRM), customer service chat (CSC) is an Internet service that allows the user to communicate in real time with a customer service agent by using an instant messaging (IM) application that's built into the company's Web site. CSC is often part of a "blended media" approach to contact center management, where customer service agents use multimedia routing technology to interact with customers by telephone, fax, e-mail, and chat. In retail e-commerce, chat is promoted as being a costeffective way to add personalization and social interaction to the online shopping experience as well as being a way to provide immediate responses to customer questions.

In this era of increased customer expectations, lengthy delays in email communications are becoming unacceptable. Many clients are hesitant to complete a purchase if they have even one unanswered question. Live support chat gives your customers answers to their questions on the spot in real-time, which increases customers' satisfaction level. Live chat fosters confidence in customers. If clients see a live chat button on your site, they will feel reassured that they will have easy access to a live person, even after the sale had been made. (Provide Support .com) 


\section{EFFECTIVENESS OF LIVE SUPPORT CHAT -A NEW THEORETICAL MODEL}

Several researchers have addressed the effectiveness of e-mail as a customer support tool (Millar 2001) and (Kannan 2011). Other has discussed online (not real-time) customer support such as filling out a form or browsing help menus. But very little research was found to discuss the effectiveness of "Live Customer Support Chat" (Lindsay 2009), although it is an important new trend in online customer service because it solves customers' problems and concerns instantly on the spot. This research project tries to fill out this research gap by examining this new type of online customer service (Live Customer Support Chat). This is a type of service that is newly implemented at some E-commerce web sites that bypasses traditional customer service types such as telephones and e-mails. We are in an era that customers are more demanding requesting their questions, problems and concerns to be solved instantly on the spot, rather than waiting to receive a replay. This is exactly what live customer support chat is all about. This research project investigates and validates this new type of customer service in e-commerce web sites, through the well-accepted and famous Service Quality Model. The investigators designed a survey questionnaire to explore the benefits and barriers of live customer support chat and the justification for e-commerce web site to implement such as service. The research project also introducers and examines for the first time the effects of E-Service quality on live customer support chat.

In this paper we introduce a new theoretical model for "Live Customer Support Chat Success". This new model is based on well-established Technology Acceptance Model (Davis 1989) and the famous Service Quality Model (Nakhai \& Neves 2009). The Technology Acceptance Model (TAM) (Figure 1 below) is an information systems theory that models how users come to accept and use a technology. The model suggests that when users are presented with a new technology, a number of factors influence their decision about how and when they will use it, notably: Perceived usefulness (PU) - This was defined by Fred Davis as "the degree to which a person believes that using a particular system would enhance his or her job performance". Perceived ease-of-use (PEOU) - Davis defined this as "the degree to which a person believes that using a particular system would be free from effort" (Davis 1989). The TAM has been continuously studied and expanded-the two major upgrades being the TAM 2 (Venkatesh \& Davis 2000 \& Venkatesh 2000) and the Unified Theory of Acceptance and Use of Technology (or UTAUT, Venkatesh et al. 2003). A TAM 3 has also been proposed (Venkatesh \& Bala 2008).

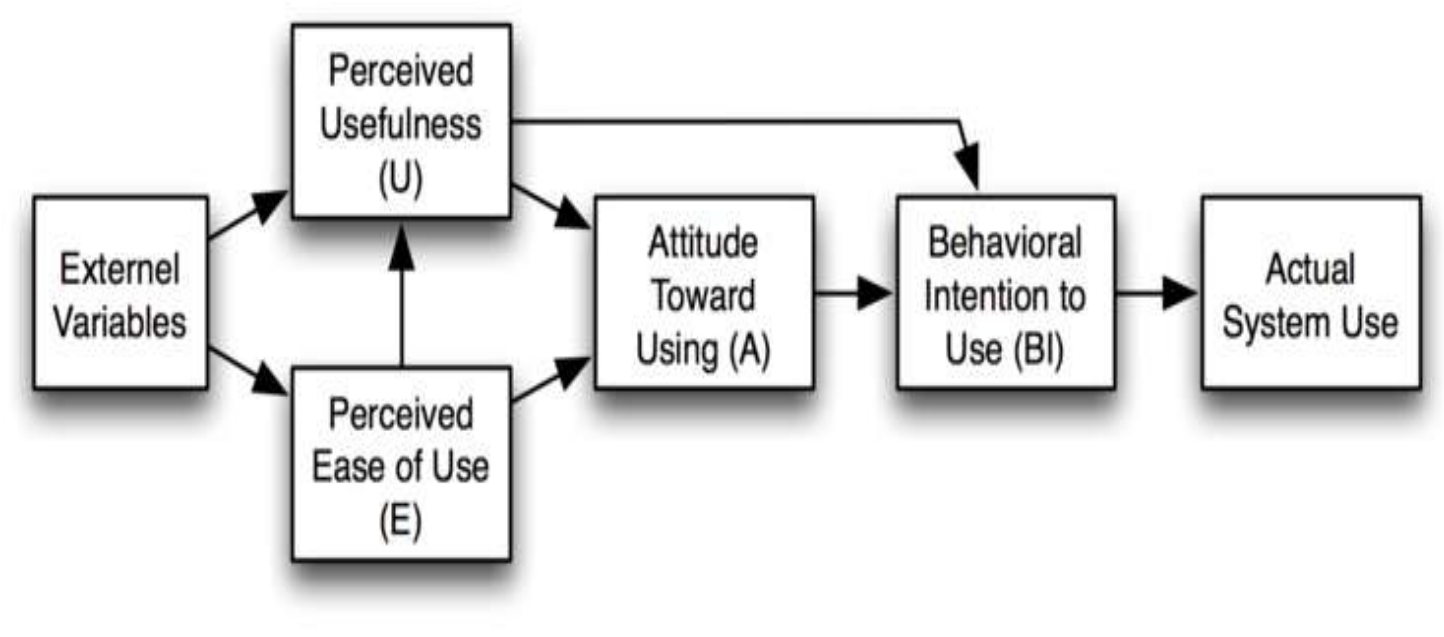

Figure 1: The Technology Acceptance Model, Version 1 (Davis 1989)

The comparison of expectations with perceptions represents the relative importance of these criteria in shaping customer expectations prior to the delivery of service may differ from their relative importance in actual customer perceptions of the delivered service. The gap between producer's specifications and customers' expectations for the service level may lead to dissatisfaction even when the producer meets the exact design 
specification. SERVQUAL was originally measured on 10 aspects of service quality: reliability, responsiveness, competence, access, courtesy, communication, credibility, security, understanding the customer and tangibles. It measures the gap between customer expectations and experience. By the early nineties the authors had refined the model to the useful acronym RATER as demonstrated in table 1 below. According to Zeithaml, Parasuraman \& Berry (1990), there are five key areas which together form the qualities of a service offering from a customer perspective. Where the Gap model describes the how the provider can minimize the perception gap RATER focuses on the dimensions of customers' expectations as demonstrated in table 1 below)

Table 1: Dimensions Of Service Quality (Servqual Or Rater) (Zeithaml, Parasuraman \& Berrey 1990)

\begin{tabular}{|l|l|}
\hline Reliability & Ability to perform the promised service dependably and accurately \\
\hline Responsiveness & Willingness to help customers and provide prompt service \\
\hline Assurance & Knowledge and courtesy of employees and their ability to convey trust and confidence \\
\hline Empathy & Caring individualized attention the firm provides its customers \\
\hline Tangibles & Appearance of physical facilities, equipment, personnel and communication materials \\
\hline
\end{tabular}

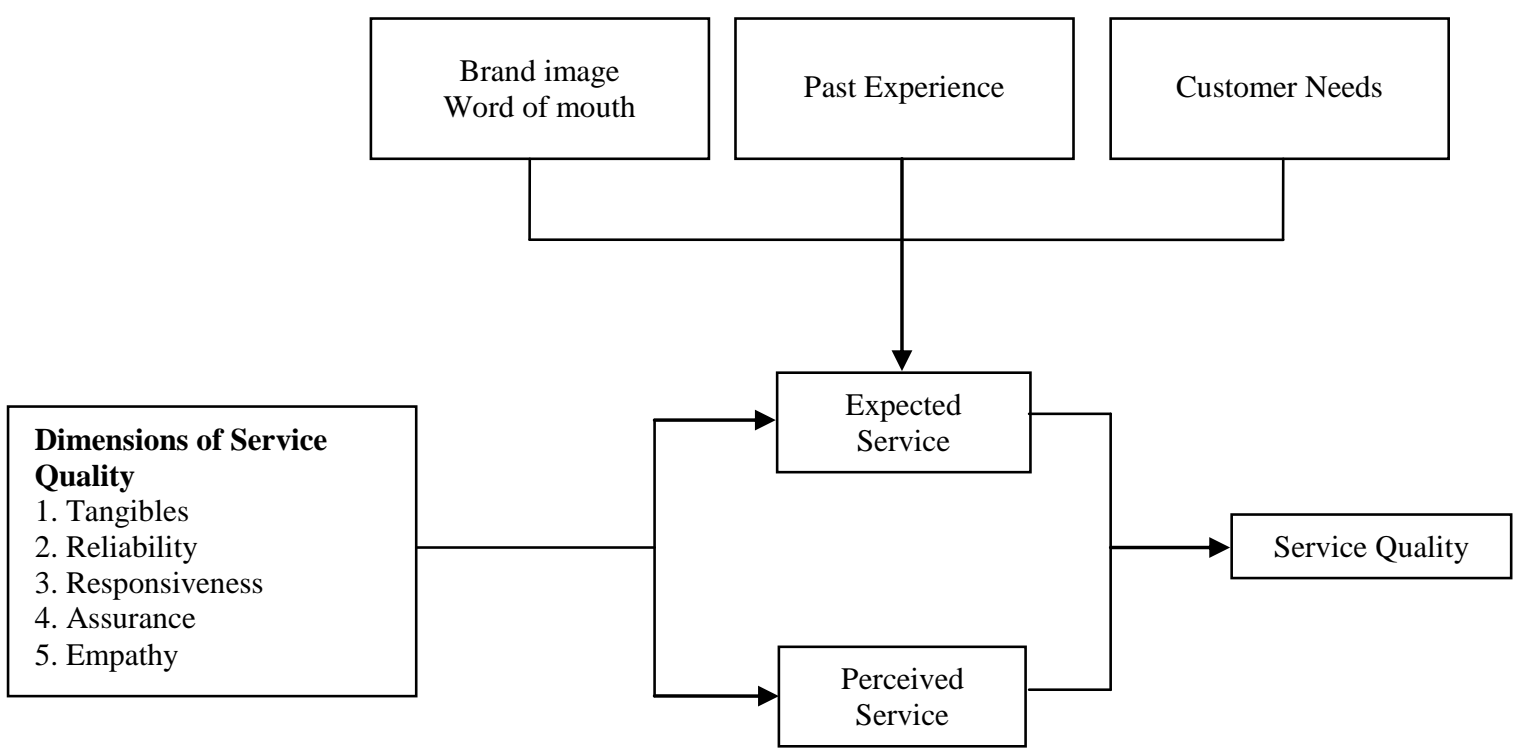

Figure 2: The Service Quality Model (Nakhai And Neves 2009)

Besides the two models we are using in this study, and in order to take in consideration the technical aspect of Live Support Chat, we have added the "Dimensions of E-Service Quality" to the model. The dimensions of EService Quality are decomposed to system quality, system reliability, system availability, information quality, consistency of service quality and online customer feedback). This way, the traditional dimensions of service quality (tangibles, reliability, responsiveness, assurance and empathy) combined with the new dimensions of Eservice quality (system quality, system reliability, system availability, information quality, consistency of service quality and online customer feedback) will affect the online customer "expected service" as well as his "perceived service". The gap between the expected service and perceived service of the live customer service chat will determine the service quality provided by that system and well as the customer satisfaction degree. 


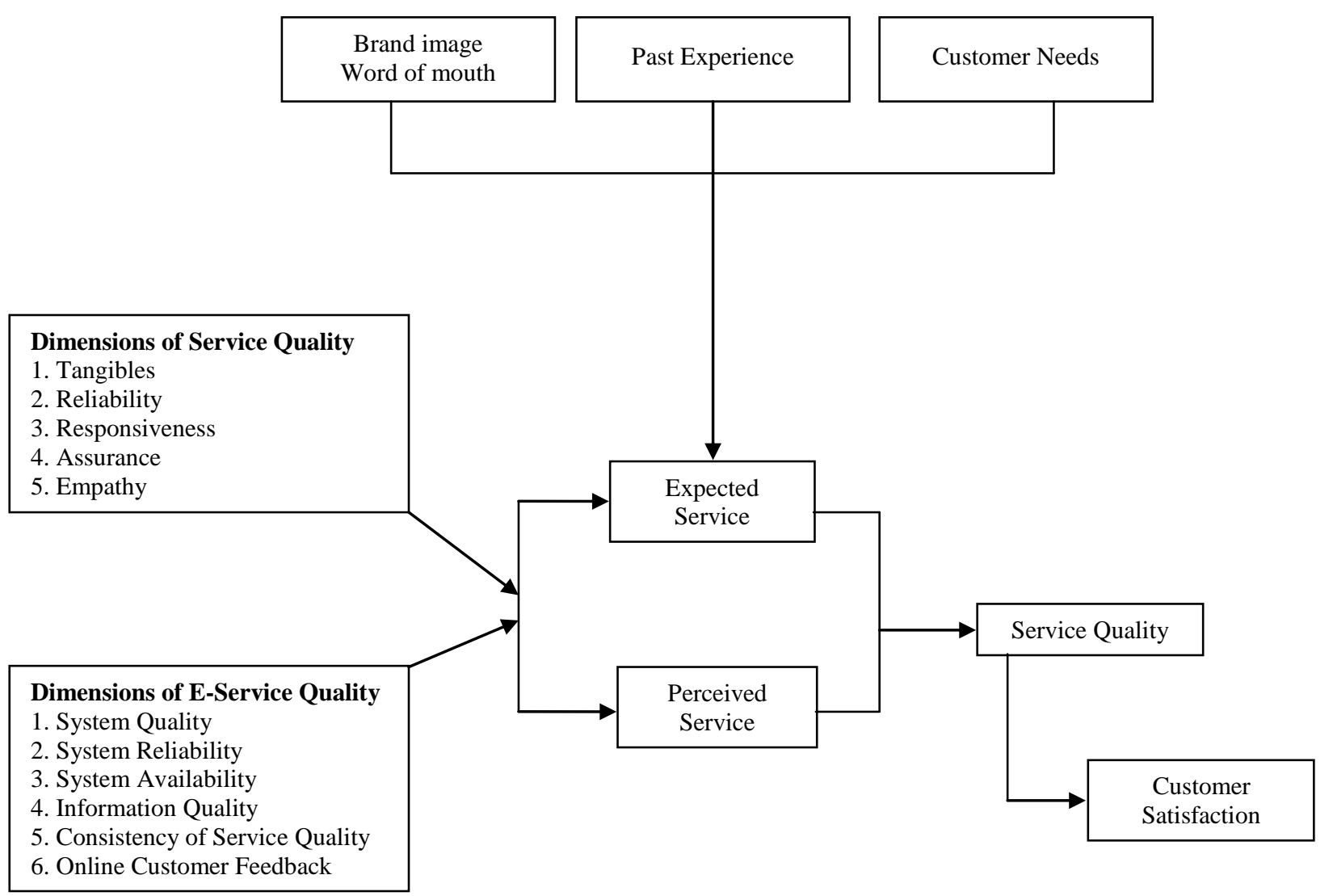

Figure 3: The Service Quality Model With The Dimensions Of E-Service Quality

(Nakhai And Neves 2009) And (Elmorshidy 2012)

The new theoretical framework for live customer support chat incorporates the dimension of service quality (tangibles, reliability, responsiveness, assurance, empathy) as well as the dimensions of e-service quality (system quality, system reliability, system availability, information quality, consistency of service quality, and online customer feedback). The model proposes that these two dimensions of service quality and e-service quality will affect the expected service and the perceived service of Live Customer Support Chat. These two will affect the actual service quality, which by its turn will affect the customer satisfaction. Both of service quality and customer satisfaction will affect perceived usefulness of the system. Service quality will affect the perceived ease of use as well. Both perceived ease of use and perceived usefulness will affect the attitude towards using the system (Live Support Char). The attitude towards using will affect the behavioral intention to use the system, which will affect the actual use of the system (Live Customer Support Chat). 


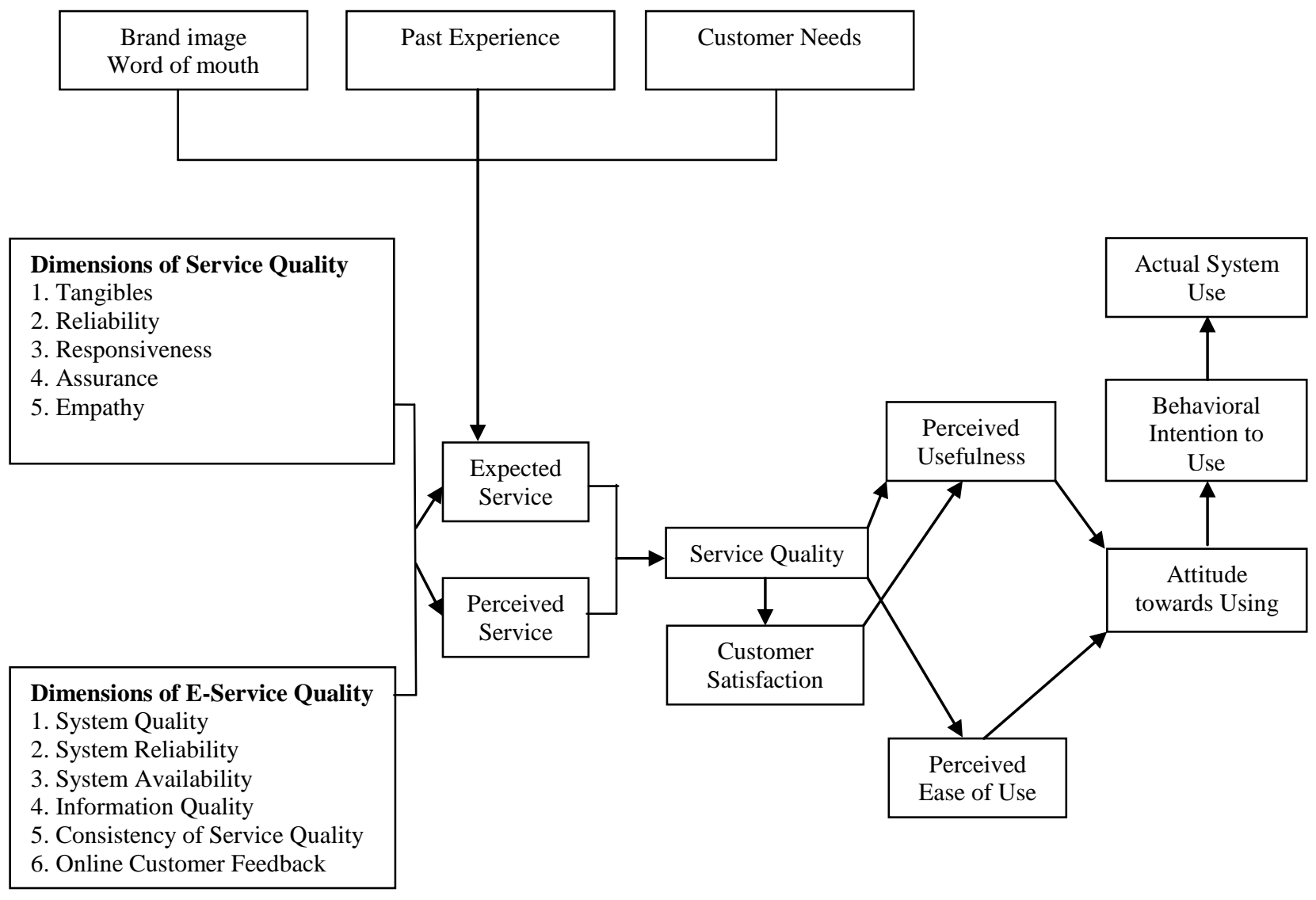

Figure 4: New Theoretical Framework For Live Customer Support Chat (Elmorshidy 2012)

\section{CONCLUSION}

Live Customer Support Chat is a new type of customer support in e-commerce websites. It bypasses the traditional non real-time customer support types such e-mail or filling out an online form. We are in a time where online customers are more demanding and they need immediate answers to their questions and concerns rather than sending an e-mail and waiting -even for a few hours- to get a response. This is exactly what Live Customer Support Chat is all about. Online chat may refer to any kind of communication over the Internet which offers an instantaneous transmission of text-based messages from sender to receiver; hence the delay for visual access to the sent message shall not hamper the flow of communications in any of the directions. Several researchers have addressed the effectiveness of e-mail as a customer support tool (Millar 2001) and (Kannan 2011). Other has discussed online (not real-time) customer support such as filling out a form or browsing help menus. But very little research was found to discuss the effectiveness of "Live Customer Support Chat" (Lindsay 2009), although it is an important new trend in online customer service because it solves customers' problems and concerns instantly on the spot. This study tried to fill this research gap by examining this new type of online customer service (Live Customer Support Chat). The study used two well-known theoretical frameworks (The Technology Acceptance Model and the Service Quality Model) and created a new dimension of E-Service quality that is based on system quality, system reliability, system availability, information quality, consistency of service quality, and online customer feedback to build a new theoretical framework/model for Live Customer Support Chat. The model proposes that the two dimensions of service quality and e-service quality will affect the expected service and the perceived service of Live Customer Support Chat. These two will affect the actual service quality, which by its turn will affect the customer satisfaction. Both of service quality and customer satisfaction will affect perceived usefulness of the system. Service quality will affect the perceived ease of use as well. Both perceived ease of use and perceived usefulness will affect 
the attitude towards using the system (Live Support Char). The attitude towards using will affect the behavioral intention to use the system, which will affect the actual use of the system (Live Customer Support Chat).

\section{CONTRIBUTION OF THE STUDY}

This study is among the first studies to address an important research gap about the effectiveness of Live Customer Support Chat, a new type of customer service implemented in E-commerce websites. The study used two well-known theoretical frameworks (The Technology Acceptance Model and the Service Quality Model) and created a new dimension of E-Service quality that is based on system quality, system reliability, system availability, information quality, consistency of service quality, and online customer feedback to build a new theoretical framework for Live Customer Support Chat. Future researchers are encouraged to test this model in different ecommerce setting and website types to see if this combination of service quality theory and technology acceptance theory will apply.

\section{AUTHOR INFORMATION}

Dr. Ahmed Elmorshidy is an assistant professor of Management Information Systems (MIS) and the Head of the Accounting and MIS department at Gulf University for Science and Technology in Kuwait. He received his Ph.D. in Management of Information Systems (MIS) in 2004 from Claremont Graduate University, Claremont, California, U.S.A. Previously he has earned an MBA in 1995 and an M.A. in Computer Resources and Information Management in 1994 from Webster University, St. Louis, Missouri, U.S.A. Dr. Elmorshidy taught at several academic institutions including Alexandria University, Webster University, Claremont Graduate University, National University, and currently at Gulf University for Science and Technology in Kuwait. Dr. Elmorshidy's research interests are focused on online information systems and the effect of new and disruptive technologies on the field of MIS (Management of Information Systems). Dr. Elmorshidy is a member of IEEE organization and in the Association of Information Systems (AIS). E-mail: Morshidy.A@gust.edu.kw

\section{REFERENCES}

1. Andrews, Dorine C. (2010), Georgetown University. Online Customer Service Chat: Usability and Sociability Issues. http://www.arraydev.com/commerce/jim/0203-01.htm

2. CRM Panel. "Benefits and advantages: Live chat software. 20 reasons why you should sign up for Live Chat Live Customer Support Software" http://crmpanel.com/c benefits.php

3. Davis, F. D. (1989), "Perceived usefulness, perceived ease of use, and user acceptance of information technology", MIS Quarterly 13(3): 319-340

4. Davis, F. D.; Bagozzi, R. P.; Warshaw, P. R. (1989), "User acceptance of computer technology: A comparison of two theoretical models", Management Science 35: 982-1003

5. FalseSheng, Hong; Siau, Keng and Nah, Fiona Fui-Hoon, "Understanding the Values of Mobile Technology in Education: A Value-Focused Thinking Approach", Database for Advances in Information Systems 41.2 (May 2010): 25-44, 6.

6. Goh, Tiong; Kinshuk, "Getting Ready for Mobile Learning-Adaptation Perspective", Journal of Educational Multimedia and Hypermedia 15. 2 (2006): 175-198.

7. Hahn, Jim, "Mobile learning for the twenty-first century librarian", Reference Services Review 36.3 (2008): 272-288.

8. Heath, Barbara; Herman, Russell; Lugo, Gabriel; Reeves, James; et al, "Developing a Mobile Learning Environment to Support Virtual Education Communities: Technological Horizons in Education", T.H.E. Journal 32. 8 (Mar 2005): 33-34, 36-37.

9. Kannan k (2011). "How Website Gain Competitive Benefits using Live Chat" Promotion World. http://www.promotionworld.com/internet/articles/110104-How-Website-Gain-Competitive-Benefits-LiveChat 
10. Kenny, Richard F; Van Neste-Kenny, Jocelyne M C; Park, Caroline L; Burton, Pamela A; Meiers, Jan’ "Mobile Learning in Nursing Practice Education: Applying Koole's FRAME Model”, Journal of Distance Education (Online) 23. 3 (2009): 75-95.

11. Kukulska-Hulme, Agnes, “Will mobile learning change language learning?”, ReCALL: the Journal of EUROCALL 21.2 (May 2009): 157-165.

12. Kurtinaitiene, Jolita, "Marketing orientation in the European Union mobile telecommunication market", Marketing Intelligence \& Planning 23. 1 (2005): 104-113.

13. Liu, Yong; Han, Shengnan; Li, Hongxiu, "Understanding the factors driving m-learning adoption: a literature review", Campus - Wide Information Systems 27. 4 (2010): 210-226.

14. Lindsay, Gillian (2009). Benefits of Live Support. http://www.wiliam.com.au/wiliam-blog/live-supportbenefits

15. Millar, Emily (2011, April 28). Online Chat - Improve Customer Service, Increase Sales. corpmagazine.com http://www.corpmagazine.com/management/sales-marketing-/itemid/4313/online-chat-improve-customer-service-increase-s'

16. Nakhai, B. \& Neves, J.S. 2009. 'The challenges of six sigma in improving service quality', International Journal of Quality \& Reliability Management, Vol. 26 No 7, pp.663 - 684.

17. Norbayah Mohd Suki; Norazah Mohd Suki, "Mobile phone usage for m-learning: comparing heavy and light mobile phone users", Campus - Wide Information Systems 24.5 (2007): 355-365.

18. Peng, Hsinyi; Su, Yi-Ju; Chou, Chien; Tsai, Chin-Chung, "Ubiquitous knowledge construction: mobile learning re-defined and a conceptual framework: Journal of the Association for Programmed Learning ETTI”, Innovations in Education and Teaching International 46. 2 (May 2009): 171-183.

19. Provide Support. "10 Reasons to use Live Chat for Business" http://www.providesupport.com/aboutus/articles/ten-reasons-to-use.html

20. Provide Support. "The Benefits of Live Chat for E-Commerce." http://www.providesupport.com/aboutus/articles/benefits-live-chat-ecommerce.html

21. Stockwell, Glenn, "Investigating learner preparedness for and usage patterns of mobile learning", ReCALL: the Journal of EUROCALL 20. 3 (Sep 2008): 253-270

22. Tien-Yu, Hsu; Hao-Ren, Ke; Wei-Pang, Yang, "Knowledge-based mobile learning framework for museums", The Electronic Library 24. 5 (2006): 635-648.

23. Wagner, Ellen, "Realizing the promises of mobile learning", Journal of Computing in Higher Education 20. 2 (Nov 2008): 4-14.

24. Wu, Tin-Yu; Chao, Han-Chieh, "Mobile e-Learning for Next Generation Communication Environment", International Journal of Distance Education Technologies 6.4 (Oct-Dec 2008): 1-13.

25. Zeithaml, Parasuraman \& Berry, "Delivering Quality Service; Balancing Customer Perceptions and Expectations," Free Press, 1990. 


\section{NOTES}

